\title{
Colored anodizing of titanium with pyroligneous solutions of black wattle
}

\author{
Luciane Taís Fuhr ${ }^{1}$, Ângela Beatrice Dewes Moura ${ }^{1}$, \\ Carlos Leonardo Pandolfo Carone ${ }^{1}$, Fernando Dal Pont Morisso ${ }^{1}$, \\ Leonardo Felix Scheffel ${ }^{1}$, Sandra Raquel Kunst ${ }^{2}$, \\ Jane Zoppas Ferreira $^{2}$, Cláudia Trindade Oliveira ${ }^{1}$
}

\author{
${ }^{1}$ ICET, Feevale University, RS-239, 2755, Novo Hamburgo, RS, Brasil. \\ ${ }^{2}$ LACOR, Federal University of Rio Grande do Sul - UFRGS, Avenida Bento Gonçalves, 9500, Porto Alegre, RS, Brasil. \\ e-mail: luciane.fuhr@gmail.com, angelab@feevale.br, carloscarone@feevale.br, morisso@feevale.br, \\ scheffel1234@gmail.com, tessaro.sandra@gmail.com, jane.zoppas@ufrgs.br, cto@feevale.br
}

\begin{abstract}
In many places, charcoal production, using Australian Blackwood, is still a rudimentary process, generating huge environmental impact, due to the release of pyrolysis smoke into the atmosphere. Both the society and governmental agencies is pushing the factories to condense the smoke, generating byproduct known as pyroligneous liquor. Although it's largely used for agricultural purpose, as a fertilizer and phytosanitizer, its chemical composition presents hydrogen and oxygen rich compounds, making it a potential electrolyte in the surface treatment industry, especially for anodization. Organic alternatives are being used to replace these electrolytes to make the anodizing process cleaner. Then, for the first time, Australian Blackwood pyroligneous liquor was used as an anodizing electrolyte for titanium TICP-G2, to obtain oxides for protection and coloring of the metal. For such, suitable parameters to execute the process were determined (dilution, current density, temperature, agitation, $\mathrm{pH}$, conductivity) and an analysis of the transient potential over time was made. The anodized surfaces were characterized using top view Scan Electronic Microscopy (SEM) and Grazing Incidence X-ray Diffraction (GIXRD). Based on the results presented, it can be concluded that the best parameters to anodize the titanium were obtained with $50 \%$ pyroligneous liquor diluted in water, obtaining colored surfaces and promoting the formation of oxide crystallites clusters mainly in longer process times (3600s).
\end{abstract}

Keywords: Pyroligneous liquor, Titanium, Anodizing.

\section{INTRODUCTION}

Environmental problems increase the interest sources in renewable energies. In order to replace the current energetic matrix based on fossil fuels, pyrolysis, which is a controlled thermal degradation of biomass rich in cellulosic material, stands out as an alternative for obtaining energy. Its use may be either direct (in a heating boiler for steam generation) or to obtain byproducts of significant commercial value, such as charcoal. Although there are still controversies, charcoal has a positive balance of carbon consumption, since the biomass used is derived from reforestation areas or co-processing techniques [1]. The last Brazilian Energy Balance, published in 2013, showed that biomass accounts for about $6 \%$ of the national energy matrix, overtaking coal $(1.25 \%)$.

The methods of charcoal production by pyrolysis are known and consolidated. However, its production is still marginalized, being developed in Brazil mainly by small farmers, who draw their livelihood from this activity. Small coaling communities installed in Vale do Rio dos Sinos, Taquari and Caí, in eastern Rio Grande do Sul, sustain an agriculture-based economy. Charcoal production became a forest cultivation byproduct, mainly based on black wattle. In this region, the city of Brochier, for example, has much of its area devoted to the cultivation of this species for the production of charcoal [2], thanks to its rugged topography. Currently, 4,500ha of the 10,500ha of the municipality are destined to the cultivation of the species, which supplies charcoal for about 500 artisanal ovens in rural properties. It is estimated that there are about 30,000 small coal producers who are established in the state of Rio Grande do Sul, using mainly black wattle as raw material, but also eucalyptus, pine and cedar. 
In Brazil, charcoal is used mainly in the steel industry [3]. Rio Grande do Sul's production, however, is primarily intended for domestic consumption and the gastronomic sector, for instance, bars and restaurants. Its consumption is closely linked to the local population cultural identity: charcoal is used as a basic ingredient in barbecue preparation, the main icon of the native cuisine of this state [4], and as fuel for fireplaces, countryside stoves and wood stoves.

The production process of charcoal in these communities is rather rudimentary, made with low technology and with little regard to process parameters or even waste generation [5]. As technology is primitive, the operational control of the decarburization furnaces is small and there is not a qualitative or quantitative control of the production [3,6]. The product of the carburization process is about $30 \%$ to $40 \%$, in other words, less than half of the total biomass is converted to charcoal. The remainder is released in the form of gases and vapors, which end up being a major problem for air pollution. The smoke from pyrolysis is composed of numerous chemical compounds (furans, alcohols, carboxylic acids, hydrocarbons, etc.) [7,8], which has led to serious discussions on sustainable development of these communities in order to prevent environmental degradation.

While in Brazil, the collection of these gases is practically ignored [7], in Japan it is a common practice to liquefy the smoke $[9,10]$, thus yielding pyroligneous liquor. This product is also known as pyroligneous liquid, pyroligneous acid, wood vinegar, liquid smoke and even bio-oil. Among the components of pyroligneous liquor, there are phenol, tar, cresols and ketones. However, its predominant ones are water (about $80 \%$ ), acetic acid and methanol. Some compounds in pyroligneous liquor have a particular commercial value, such as acetol, which can be used in pharmaceutical industry. The development of techniques and technologies that promote pyroligneous liquor to the status of raw material can add value to the collection processes. With this perspective, small farmers could favor cleaner, controlled and sustainable processes, ensuring environmental integrity and continuously improving the process.

The use of pyroligneous liquor has been, for many years, empirical in agriculture [11]. It has been added to the environment without regard to its disposal or possible effluent treatment. This leads to the possibility pyroligneous liquor' utilization as an electrolyte in anodizing industries, in which wastewater treatment is a bottleneck.

In this context, the anodizing process may be the most indicated among galvanic processes, since the layer is made of metal from the anodized substrate itself, not requiring the deposition of metal from the electrolyte. The anodizing process gives to the metal an anticorrosive protection, and in the case of titanium, its use is widespread in the jewelry and biomedicine industries. In the case of titanium, the most common electrolytes used in anodizing processes are sulfuric acid $-\mathrm{H}_{2} \mathrm{SO}_{4}$, phosphoric acid - $\mathrm{H}_{3} \mathrm{PO}_{4}$ [12] and acetic acid $\mathrm{CH}_{3} \mathrm{COOH}$ [13]. In anodizing in $\mathrm{H}_{2} \mathrm{SO}_{4}$, the obtained surface is usually microporous, where the pores are produced by spark. In anodizing in acetic acid, or solutions containing acetate, grooves or structures with large depressions are formed [14]. Xie et al [14] determined that in the galvanostatic process, the acetate ion $\left(\mathrm{CH}_{3} \mathrm{COO}^{-}\right)$solubilizes the amorphous titanium oxide of the barrier layer formed in the initial stages of anodization.

Quintero et al [15] verified a strong dependence of current density on the thickness and kinetics of the formation of anodized Ti-CP2 films, using $1.5 \mathrm{M} \mathrm{H}_{2} \mathrm{SO}_{4}+0.3 \mathrm{M} \mathrm{H}_{3} \mathrm{PO}_{4}$ electrolyte. Comparing oxides grown by galvanostatic anodization at $15 \mathrm{~mA} / \mathrm{cm}^{-2}$ and $55 \mathrm{~mA} / \mathrm{cm}^{-2}$, the author identified the formation of a duplex oxide in all samples: the oxide layer adjacent to the metal is thin and compact (typical structure of barrier oxide), and on it grows another layer, thicker, of porous film. The formation of pores [15] is associated with the generation of sparks, and the phenomenon generates temperature increase, causing localized fusion in the formed oxide. The molten oxide point is rapidly cooled by the surrounding electrolyte, and is characterized by depression in the oxide, which forms the pore $[16,17,18]$.

Xing et al [19] studied the evolution of the titanium oxide layer when obtained by potentiostatic anodization in $0.1 \mathrm{M} \mathrm{H}_{2} \mathrm{SO}_{4}$, with application of $10 \mathrm{~V}$ and $30 \mathrm{~V}$. The results showed clearly that "like flowers" concretions are formed from 10 minutes of anodization only at $30 \mathrm{~V}$ potential, but they do not appear if the voltage used is $10 \mathrm{~V}$. Xing et al [19] associated the behavior difference in the two potentials analyzed by the oxide formation dynamics. At 10V, there is little OER (Oxygen Evolution Reaction), so oxygen bubbles are "adsorbed" briefly on the metal / electrolyte interface. The oxide grows around the bubble, which then detaches, forming a micropore. The thickening of the anodized layer occurs with increasing the anodizing time (this process is known as oxide aging). In $30 \mathrm{~V}$, on the other hand, there is a large OER, which causes nanocrystals to appear in amorphous oxide, which act as ionic conduction channels, and evolve into concretions like flowers. The thickening of the oxide occurs with $\mathrm{TiO} 2$ already crystallized, which presents a rough appearance. 
In order to add value to pyroligneous liquor, making its use viable in other sectors, and taking into account its easy obtention and disposal and the fact that its predominant constituent is acetic acid, this work will study viability of utilization of pyroligneous liquor as electrolyte for anodizing. This study aims at anodizing the titanium with pyroligneous liquor, evaluating the main parameters of anodizing, such as electrolyte concentration, current density, potential for obtaining titanium oxides, and characterizing the oxides obtained, regarding morphology and crystalline structure.

\section{MATERIALS AND METHODS}

\subsection{Substrate}

Commercially pure titanium of grade 2 - TiCP 2 was used as substrate to anodizing, in accordance to ASTM B348-11 (Table 1), in sheet form with thickness of $1 \mathrm{~mm}$.

Table 1: Chemical composition of the plate and bar of TiCP 2 used in this research.

\begin{tabular}{c|c}
\hline ELEMENT & $\%$ \\
\hline $\mathrm{N}$ & 0.03 \\
\hline $\mathrm{C}$ & Máx. 0.08 \\
\hline $\mathrm{H}$ & 0.015 \\
\hline $\mathrm{Fe}$ & 0.3 \\
\hline $\mathrm{O}$ & 0.25 \\
\hline $\mathrm{Ti}$ & Balance \\
\hline Other & 0.1 \\
\hline
\end{tabular}

The titanium sheet was cut into samples with dimensions of $15 \mathrm{~mm}$ x $10 \mathrm{~mm}$. A hole was made near the top edge, centered, through which a copper wire passed to allow electrical contact with the electric current source. The junction of the copper wire was coated with titanium epoxy resin for insulation, and the exposed surface of each sample for anodizing was $3 \mathrm{~cm}^{2}$. The samples were pickled in a solution of $\mathrm{HF}_{\mathrm{HNO}} \mathrm{HN}_{3}$, proportions of $1: 3$, for $6 \mathrm{~s}$, immediately before anodizing to remove the native oxide, so as not to influence the growth of oxide in the anodized layer. Afterwards, they were rinsed in deionized water.

\subsection{Anodizing electolytes}

Pyroligneous liquor solutions were used as electrolytes for anodizing. Pyroligneous liquor used in this study was obtained from the charcoal burners from Vale do Rio dos Sinos region, in Rio Grande do Sul. The liquor came from black wattle pyrolysis (Acacia mearnsii De Wild) for charcoal production, and underwent a decantation process of 3 months. The liquor had reddish brown color, was translucent and had a strong smoky odor. The composition of pyroligneous liquor used in this study was determined by Furtado et al. [20]. The liquor was diluted in $25 \% \mathrm{v} / \mathrm{v}$ and $50 \% \mathrm{v} / \mathrm{v}$ with deionized water. The pure pyroligneous liquor was also used as electrolyte. Dilution of the main electrolyte is also a study parameter.

Pyroligneous liquor was further distilled to minimize the pronounced color of the solution, thus allowing us to better visualize the samples during anodizing. The liquor distilled was translucent and colorless, but the characteristic odor remained. After the distillation process, the condensed liquid was diluted with 50\% deionized water, and this solution was also used as electrolyte. However, this electrolyte was used only for better visualization of the formation of interfering color laboratory phenomenon, since it is of great importance to maximize its use industrially, which involves adding the lowest possible cost.

For comparison of data with literature, sulfuric acid $\left(\mathrm{H}_{2} \mathrm{SO}_{4} 1 \mathrm{~mol} . \mathrm{L}^{-1}\right)$ [21-23] and acetic acid [24, 25] were used as control electrolytes. The electrolytes were disposed after $3600 \mathrm{~s}$ of anodizing. Table 2 summarizes the electrolytes used and their concentrations. 
Table 2: Electrolytes used for anodizing.

\begin{tabular}{c|c}
\hline ELECTROLYTE & IDENTIFICATION \\
\hline Raw pyroligneous liquor 25\% & $\mathrm{pl} \mathrm{25 \%}$ \\
\hline Raw pyroligneous liquor $50 \%$ & $\mathrm{pl} 50 \%$ \\
\hline Raw pyroligneous liquor $100 \%$ & $\mathrm{pl} \mathrm{100 \%}$ \\
\hline Distilled pyroligneous liquor $50 \%$ & Distilled 50\% \\
\hline $\mathrm{H}_{2} \mathrm{SO}_{4}$ Sulfuric acid $1 \mathrm{~mol} . \mathrm{L}^{-1}$ & $\mathrm{H}_{2} \mathrm{SO}_{4} 1 \mathrm{~mol} . \mathrm{L}^{-1}$ \\
\hline Acetic acid 1 mol.L & $\mathrm{AA} 1 \mathrm{~mol} . \mathrm{L}^{-1}$ \\
\hline
\end{tabular}

\subsection{Anodizing}

Anodizing was performed in galvanostatic mode. The evolution of the potential developed in the samples according to the process time was monitored. For the anodizing process, current density of $1 \mathrm{~mA} \cdot \mathrm{cm}^{-2}$ was used, applied by external power source, with $80 \mathrm{rpm}$ stirring at room temperature $\left(25^{\circ} \mathrm{C}\right)$. Two platinum cathodes in the form of coiled wire were used, one on each side of the sample, to ensure the equal growth of oxide on the titanium surface. The cathodes were placed parallel to and equidistant from the sample. The experiments were performed in triplicate in a current source of $500 \mathrm{~mA}$ and potential of $300 \mathrm{~V}$ for $300 \mathrm{~s}, 600$ s, $1800 \mathrm{~s}$ and $3600 \mathrm{~s}$. The source was connected to a computer which had a software to collect the anodizing process data. After the anodizing, the samples were rinsed with deionized water and cold-air dried.

\subsection{Characterization}

For the morphological characterization of the anodized surfaces, it was used a scanning electron microscope JEOL JSM-6510CV with $129 \mathrm{eV}$ of resolution. The anodized samples were metallized with a thin gold film.

Crystallographic characterization of anodic films on the surfaces of the obtained samples was carried out by Grazing Incidence X-ray Diffraction (GIXRD). The equipment used for the tests was a Shimadzu XDR-7000 diffractometer, using the incidence technique of X-ray beam at low angle. The equipment has an $\mathrm{X}$-ray generator tube with $\mathrm{Cu}$ target, which has a $\mathrm{K} \alpha$ radiation of $1.5406 \AA$. The beam and the specimen surface were angled at 1 degree and the acceleration voltage of the X-ray tube was $40 \mathrm{kV}$. A $25 \mathrm{~mA}$ of current was applied to the X-ray tube, the scan ranging from 15 to 80 degrees. The scan rate used was 1.2 degrees/min. As the sample was thin and narrow, it was placed on a carrier that does not generate diffraction peaks (non-reflecting material) supplied by the equipment manufacturer. X'Pert HighScore was the software used for analyzing the results and comparing with standard spectra database. For GIXRD measurements, a controlled diffractometer with a configuration called "Seemann-Bohlin geometry" was used, different from the conventional geometry, called "Bragg-Brentano".

\section{RESULTS AND DISCUSSION}

\subsection{Potential transients}

Titanium samples were anodized for $3600 \mathrm{~s}$, presenting different behavior over anodizing time. Accordingly, for better work understanding, the anodizing curve produced up to $300 \mathrm{~s}$ will be shown and discussed first, followed by the curve obtained up to $3600 \mathrm{~s}$.

Figure 1 shows the potential transient of titanium samples anodized in pyroligneous liquor, acetic acid and sulfuric acid up to $300 \mathrm{~s}$. It was observed that the curves exhibit similar behavior regardless of the anodizing electrolyte. Curves show a sharp increase in potential with time up to 300s, with two distinct regions. 


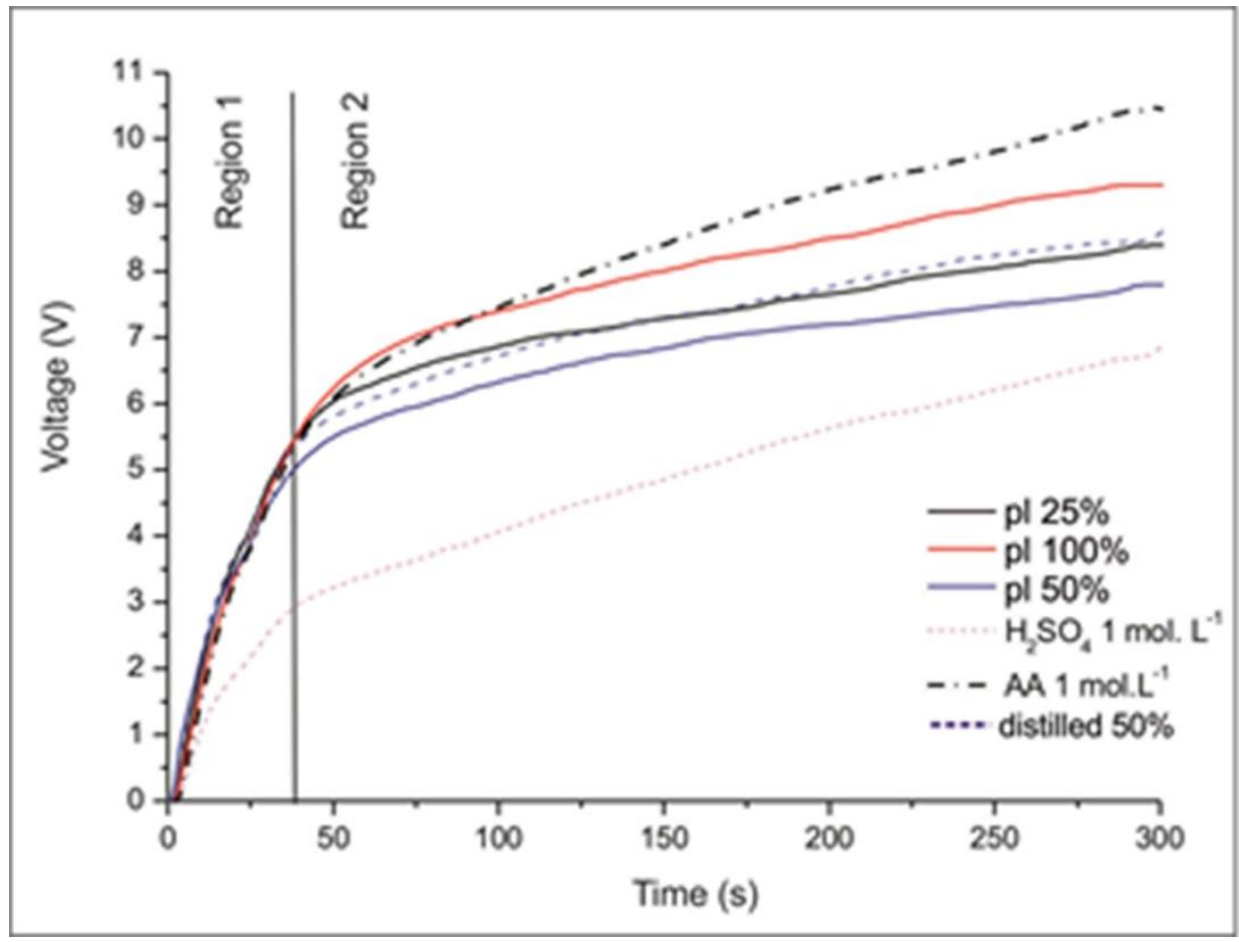

Figure 1: Potential transients versus time of the samples anodized in different electrolytes ( $300 \mathrm{~s})$.

In Figure 1, region 1 shows a linear increase in potential with time, known as anodizing rate $(\partial \mathrm{V} / \partial \mathrm{t})$. This behavior is characteristic of barrier oxide film growth in which all the applied current is used for forming oxide. In this region, $\partial \mathrm{V} / \partial \mathrm{t}$ remains constant. The behavior shown has been observed in other studies of titanium anodizing with various operating conditions [21,26,27]. In Region 1, $\partial \mathrm{V} / \partial \mathrm{t}$ showed similar results for the electrolyte containing pyroligneous liquor and the electrolyte containing acetic acid (AA) 1 mol.L $\mathrm{L}^{-1}$, and was higher than the $\mathrm{H}_{2} \mathrm{SO}_{4} 1 \mathrm{~mol} . \mathrm{L}^{-1}$ electrolyte. It is known that the pyroligneous liquor has acetic acid in its composition, which explains their similar behavior. For the GC/MS characterization of the pyroligneous extracts, a dilution step was necessary prior to the chromatographic analysis due to the presence of a significant amount of acetic acid and other organic acids, which could potentially damage the chromatographic column [20].

In region 1, the samples anodized in pyroligneous liquor and AA 1 mol. $\mathrm{L}^{-1}$ showed maximum potential ranging between $4.8 \mathrm{~V}$ and $5.5 \mathrm{~V}$, generating anodizing rates near $0.17 \mathrm{~V} . \mathrm{s}^{-1}$ (Table 3). Diamanti and Predeferri [21] anodized titanium in various $\mathrm{H}_{2} \mathrm{SO}_{4}$ concentrations as electrolyte and applied current densities ranging from $200 \mathrm{~A} . \mathrm{m}^{-2}$ to $1080 \mathrm{~A} . \mathrm{m}^{-2}$. The authors observed an anodizing rate of $2.9 \mathrm{~V} . \mathrm{s}^{-1}$ in $\mathrm{H}_{2} \mathrm{SO}_{4} 1$ mol. $\mathrm{L}^{-}$ ${ }^{1}$ with application of $200 \mathrm{~A} . \mathrm{m}^{-2}$. This value is in accordance with the anodizing rates, approximately $0.17 \mathrm{~V} . \mathrm{s}^{-}$ ${ }^{1}$ at $1 \mathrm{~mA} . \mathrm{cm}^{-2}$, presented in this study. According to Young [28], $\partial \mathrm{V} / \partial \mathrm{t}$ is approximately proportional to the current density applied in the anodic process, varying from 0.1 to 10 times its value.

Table 3: Anodizing rates, in V/s, found for the anodized samples in electrolytes based on pyroligneous liquor.

\begin{tabular}{l|c|c|c|c}
\hline ELECTROLYTES & 300 S & 600 S & 1800 S & 3600 S \\
\hline pl 25\% & $0.183 \pm 0.046$ & $0.194 \pm 0.042$ & $0.196 \pm 0.034$ & $0.187 \pm 0.011$ \\
\hline pl 50\% & $0.164 \pm 0.030$ & $0.161 \pm 0.031$ & $0.183 \pm 0.012$ & $0.177 \pm 0.015$ \\
\hline pl 100\% & $0.176 \pm 0.005$ & $0.181 \pm 0.022$ & $0.164 \pm 0.007$ & $0.180 \pm 0.014$ \\
\hline Distilled 50\% & $0.185 \pm 0.041$ & $0.175 \pm 0.021$ & $0.170 \pm 0.036$ & $0.185 \pm 0.019$ \\
\hline
\end{tabular}

The transition from region 1 to region 2 of the anodizing curve (Figure 1) is accompanied by a decrease in $\partial \mathrm{V} / \partial \mathrm{t}$. According to some authors [27,29], in valve metals, this change in curve's slope may be due to the sparking process accompanied by a dielectric breakdown of the film. However, in the anodizings carried out in this study, no characteristic which could identify sparking was observed. Literature shows that the sparking potential for anodized titanium samples occurs at potentials above 100V [27,29,30].

On the other hand, this change in the curve's slope was accompanied by oxygen presence at the anode, indicating that the water oxidation reaction and other compounds present in the liquor may have become 
the prevailing reaction in relation to the oxide formation. According to Liu et al. [27], the change in slope of the curve occurs due to a decrease in the resistivity of the oxide, and the author suggests that tha anodization reaction happens due to the ionic transport instead of the electronic one. In region 2, as the time of anodizing is small (300 s), the oxide continues increasing its in thickness, characterized by the new increase in the potential curve, up to the maximum potential (Emax), at the end of the process. Figure 2 shows the behavior of the potential over time until $3600 \mathrm{~s}$ of anodizing.

The maximum potentials (Figure 2) varied as a function of the electrolyte and its concentration. The maximum potential is related to the dynamics of the formation and dissolution of the oxide, a phenomenon that occurs simultaneously. More concentrated solutions promote dissolution. In the case of the samples, a similar behavior was observed among the transients, with small variations of potential. The low current density can influence the intensities obtained for the potential transients, as it generates anodic growth at steady state.

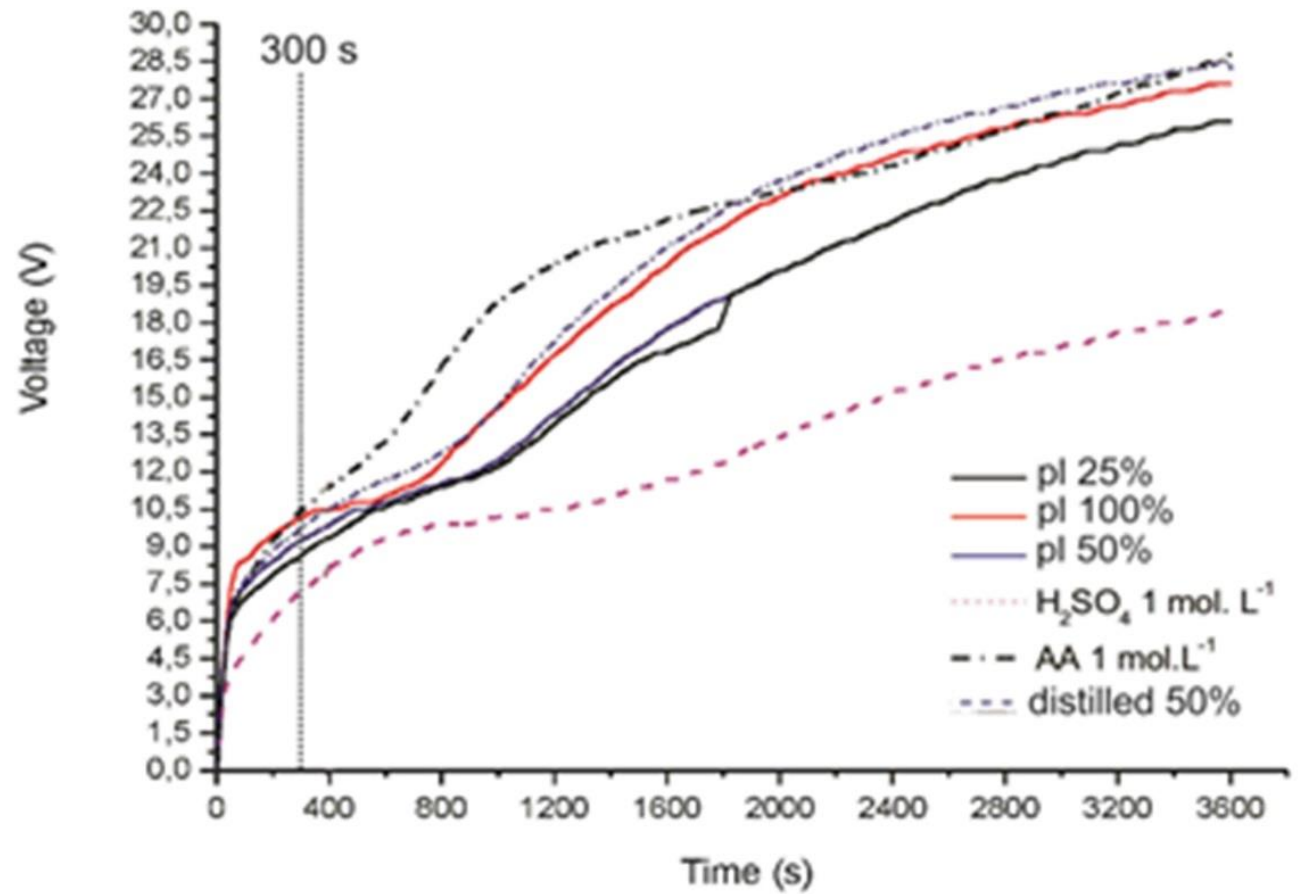

Figure 2: Potential transients versus time of the samples anodized in different electrolytes (3600 s).

The maximum potential generated, as well as the behavior of transients (Figure 2), suggest that there is only barrier type oxide, because there is no electrical evidence of oxide breakdown, leading to the formation of a porous layer. The curves show no oscillation in the potential, maintaining the direction of its growth. Literature reports similar behavior in some studies [21,24,25,31], mainly associated with titanium coloring process for decorative purposes, such as jewelry [31].

In general, electrochemical behavior of the anodic growth of titanium oxide is due to the electrochemical dynamic established between formation and dissolution rates of the film [24,25]. These rates depend on the nature of the electrolyte [28]. The potential transients of the samples presented in Figure 2 show that there is a similar behavior between the electrolytes based on pyroligneous liquor and AA 1 mol. $\mathrm{L}^{-1}$, which can be associated to their similar nature. Thus, it is possible to infer that the acetic acid present in pyroligneous liquor is primarily responsible for the anodic response of the studied systems.

Starting at $300 \mathrm{~s}$, the potential continues increasing for pyroligneous liquor electrolytes and acetic acid, but with variations in the rate $\partial \mathrm{V} / \partial \mathrm{t}$. After $300 \mathrm{~s}, \partial \mathrm{V} / \partial \mathrm{t}$ decreases, until reaching approximately $800 \mathrm{~s}$, followed by a further increase and a further decrease. This cyclical behavior indicates that the sample surface creates conditions for oxide formation. A likely explanation for this would be the formation of amorphous oxide in the first stage (up to $300 \mathrm{~s}$ ), which crystallizes, and after that, continues to form oxide. This may be associated with the change of color observed during anodizing.

Another hypothesis to explain this behavior would be the disruption of the film surface at some points. According to literature, this disruption can occur by two mechanisms: either a dielectric breakdown potential 
is greater than $100 \mathrm{~V}$ [26]; or by mechanical disruption due to internal tensions arising from the volumetric growth of the oxide $[28,32]$.

According to Xie et al. [33], anodizing made in electrolytes containing acetate ion produces $\mathrm{TiO}$ $\left(\mathrm{CH}_{3} \mathrm{COO}\right)_{2}$, that, in the presence of water, is responsible for the dissolution of the amorphous oxide barrier layer formed in the process early stages. This localized dissolution would be proportional to the concentration of acetate ion in the electrolyte and the current density used. In this study, a low current density $\left(1 \mathrm{~mA} . \mathrm{cm}^{-2}\right)$ is used, which could lead to a homogeneous dissolution of the film in the case of electrolytes containing AA (including the ones based on pyroligneous liquor). This fact can explain the changes in $\partial \mathrm{V} / \partial \mathrm{t}$ found in longer times of anodizing.

\subsection{Analysis of chromatic behavior - visual aspect of the samples}

Figure 3 shows photographs of titanium samples after being anodized in pyroligneous liquor, as well as with $\mathrm{H}_{2} \mathrm{SO}_{4}$ and acetic acid control electrolytes. A different chromatic aspect in the samples was observed, in accordance with electrolyte and anodizing time. The formation of the color interference phenomenon is an indication of an oxide layer on metal. The light interference phenomenon is reported for thin oxide films, so that they are still transparent, but colored. The color perceived bears direct relation to the film's thickness, according to Bragg's Law of interference [34].

According to literature $[24,34,35]$, the change in color indicates the formation of a thin oxide film on the surface of the substrate, resulting from the anodizing process. This change is associated with a variation in the potential and the thickness of the formed film [25]. For each employed potential during anodizing, there is a distinct color, which may change according to the nature of the electrolyte or the time of anodizing. Similar hues were obtained in the same anodizing times using pyroligneous liquor at different concentrations, in addition to the control electrolytes. However, differences between colors in hues are observed in the samples, as shown in Figure 3.

Sul et al. [24] observed that, although the oxide thickness is the main coloring agent, the nonuniformity of the layer can influence the color spectrum obtained in anodized titanium. Thus, small changes in color may be the result of these characteristics, even if the thickness of the oxide is related to the anodizing times.

The colors observed in anodized samples change hue according to the time duration of the process, which agrees with the studies of Delplancke et al. [34], Diamanti et al. [22,31], Gils et al. [36] and Karambakhsh et al. [37]. Different times of anodizing also lead to different thicknesses of thin films. According to Diamanti et al. [31], for diluted acid solutions, the growth rates of titanium oxides at low potentials are around $2 \mathrm{~nm} . \mathrm{V}^{-1}$. As end potentials generated (Figure 2) are between $8 \mathrm{~V}$ and $27 \mathrm{~V}$, this indicates that the formed films in $300 \mathrm{~s}$ have $18 \mathrm{~nm}$ and in $3600 \mathrm{~s}$ have $54 \mathrm{~nm}$, taking the minimum and maximum time as reference.

For the times of $300 \mathrm{~s}$ and $600 \mathrm{~s}$, yellow tones were obtained. The curves representing these anodizing times (Figure 1 and Figure 2) show that the final potentials reached are similar for all pyroligneous liquor dilutions, which justifies them having the same hue. Final potentials are very similar, varying from $8 \mathrm{~V}$ to 10 $\mathrm{V}$. For the $10 \mathrm{~V}$ to $12 \mathrm{~V}$ range, Sul et al. [24], who worked with sulfuric acid 1 mol.L ${ }^{-1}$, also obtained yellow hues, which agrees with the results achieved in this study. $\mathrm{H}_{2} \mathrm{SO}_{4}, \mathrm{AA}$ and distilled pyroligneous liquor samples produced a lighter yellow film, suggesting that it is formed less thick. In fact, according to the potential transient curves for time (Figure 1 and Figure 2), the final potentials generated in these samples are lower (approximately $8 \mathrm{~V}$ ) than the potential developed in the anodizing with different concentrations of raw pyroligneous liquor $(9 \mathrm{~V}$ to $10 \mathrm{~V}$ ). This fact justifies the changes in colors, because of the small variations in thickness between them, suggested by their potentials.

Among shorter and longer times of anodizing, the change of hue is well marked. The colors change from yellow to purple at shorter times and to blue at longer times. At $1800 \mathrm{~s}$ of anodizing, the generated hue is blue, developing final potentials between $18 \mathrm{~V}$ and $22 \mathrm{~V}$. It is striking that the anodized sample in pyroligneous liquor $100 \%$ is clear blue. The anodizing curve of this sample shows the final potential of $22 \mathrm{~V}, 4 \mathrm{~V}$ higher than the ones developed by pyroligneous liquor $25 \%, 50 \%$ and distilled pyroligneous liquor $50 \%$ samples. This result agrees with the chromatic scale by Diamanti et al. [22] for thin titanium film, which starts at yellow, followed by purple, blue and light blue, in direct dependence on the thickness of the oxide and final potential generated. Zaniolo [38], in his study with AA $0.1 \mathrm{~mol} . \mathrm{L}^{-1}$ and $0.5 \mathrm{~mol} . \mathrm{L}^{-1}$, also obtained bluish hues for a $20 \mathrm{~V}$ to $40 \mathrm{~V}$ potential range. Sul et al. [24], however, got a different color series for potentials close to $20 \mathrm{~V}$ in the anodizing of Ti-CP G1, according to the electrolyte, concentration, time and current density used: 
dark purple $\left(\mathrm{H}_{2} \mathrm{SO}_{4} 1 \mathrm{~mol} . \mathrm{L}^{-1}, 15 \mathrm{~mA} . \mathrm{cm}^{2}\right.$, for $2 \mathrm{~s}$ ); dark orange (AA $0.1 \mathrm{~mol} . \mathrm{L}^{-1}, 5 \mathrm{~mA} . \mathrm{cm}^{2}$, for $2 \mathrm{~s}$ ), blue (AA 1 mol.L $\mathrm{L}^{-1}, 5 \mathrm{~mA} . \mathrm{cm}^{2}$, for $11.5 \mathrm{~s}$ ), orange (acid phosphoric $1 \mathrm{~mol} . \mathrm{L}^{-1}, 5 \mathrm{~mA} . \mathrm{cm}^{2}$, for $6.5 \mathrm{~s}$ ). These changes in the usual color scale are assigned by the authors to stoichiometric differences in the film, as the presence of distinct phases and defects. In this study, however, the presence of those differences, if any, does not seem to affect the interference color, because the hues are similar to each other, for the same anodizing time.

In an overview analysis, the colors obtained for all electrolytes used are similar for the same anodizing time, suggesting that the potential gradient prevails as a film forming factor, and not the nature of the electrolyte. In fact, as shown in Diamanti et al. [21,31], this study indicates that there is a direct dependence of the oxide growth with the developed potentials. In turn, the developed potentials have a direct relationship with the anodizing time to the current density used. This dependency in the film formation and the generated interference color was also perceived by Deplancke et al. [34], in a pioneer study of interference phenomena in thin films of anodic oxides on titanium.

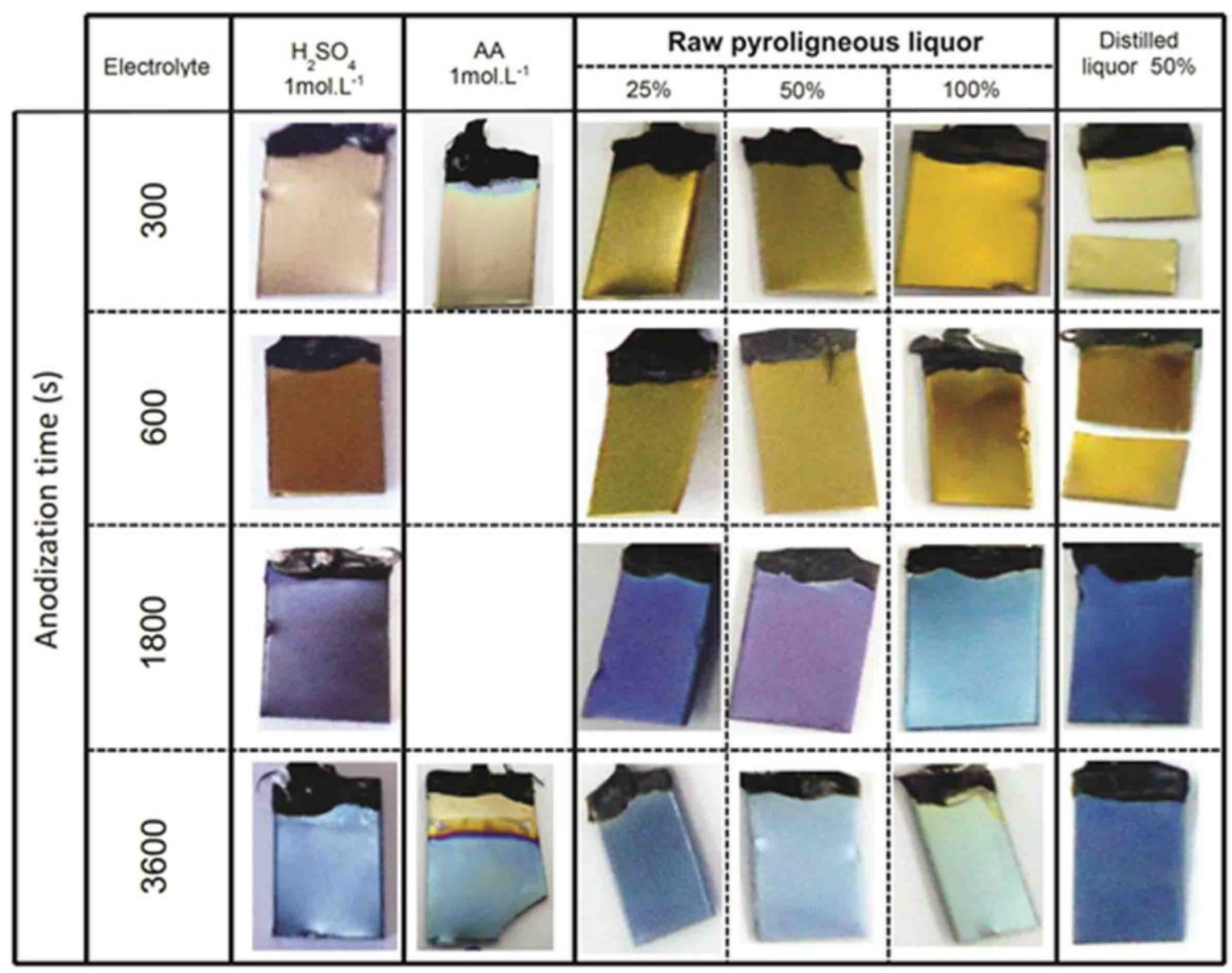

Figure 3: Photographs of the anodized samples chromatic behavior.

\subsection{Evaluation of the crystalline structure by GIXRD}

Although the results obtained for all anodizing conditions presented for the potential transients and for the visual aspect, the homogeneity of the samples was more consistent using pyroligneous liquor $50 \%$ as electrolyte. Colors obtained were compared only visually, because the greatest interest was to confirm if the electrolyte could to promote the anodizing. The obtained interfering colors and the transient curves from replicas of this electrolyte were more similar than the other electrolytes. Therefore, samples anodized in pyroligneous liquor $50 \%$ were chosen for further characterization analysis.

Figure 4 shows the GIXRD patterns for the electrolyte of pyroligneous liquor $50 \%$ where the curve referred to as "Ti" is pure titanium after pickling. The lack of X-ray diffraction patterns characteristic of either anatase or rutile may indicate either amorphous oxide or poorly crystallized anodic oxides, consisting of ultrafine crystallites beyond the sensitivity of the used equipment. The thin oxide film is thus neither amor- 
phous nor cyrstalline but behaves more like a molecular layer [25,39]. Literature reports that $\mathrm{TiO}_{2}$ oxides formed by anodizing at high potentials (up to $70 \mathrm{~V}$ ) are composed of the anatase phase [25,40,41]. However, in this study, peaks of this phase were not expected, since the anodizing was carried out by applying $1 \mathrm{~mA}$. $\mathrm{cm}^{-2}$, resulting in maximum potentials during anodizing, below $30 \mathrm{~V}$ for longer times of the process (Figure 2). In $300 \mathrm{~s}$, only the titanium peaks appear, which suggested the formed oxide film has an amorphous structure at an early stage. However, it should be noted that the technique does not present the necessary sensitivity for confirmation of the hypothesis.

The most significant intensity of the titanium peaks in other anodizing times sug-gests that the layer formed is neither totally amorphous nor crystalline and due that the oxide film is so thin probably [21]. This fact agrees with the results in the potential-transient (figure 2), where-the maximum potential achieved in $3600 \mathrm{~s}$ is $28.5 \mathrm{~V}$ for $50 \%$ pyrolignous as electrolyte.

According to the literature [21, 35], the film growth rate of Ti is $2 \mathrm{~nm} . \mathrm{V}^{-1}$, which leads to a thickness of $57 \mathrm{~nm}$ for the anodized film in 3600s. It was expected that the characteristic peaks of titanium lessened intensity in diffraction spectrum with anodizing time, assuming the increase in film thickness [22]. However, the titanium peaks at $35^{\circ}, 38^{\circ}$ and $40^{\circ}$ [41] remained, and another appeared, which suggested the presence of titanium at the peak of $53^{\circ}$, that was also observed by Song et al. [41].

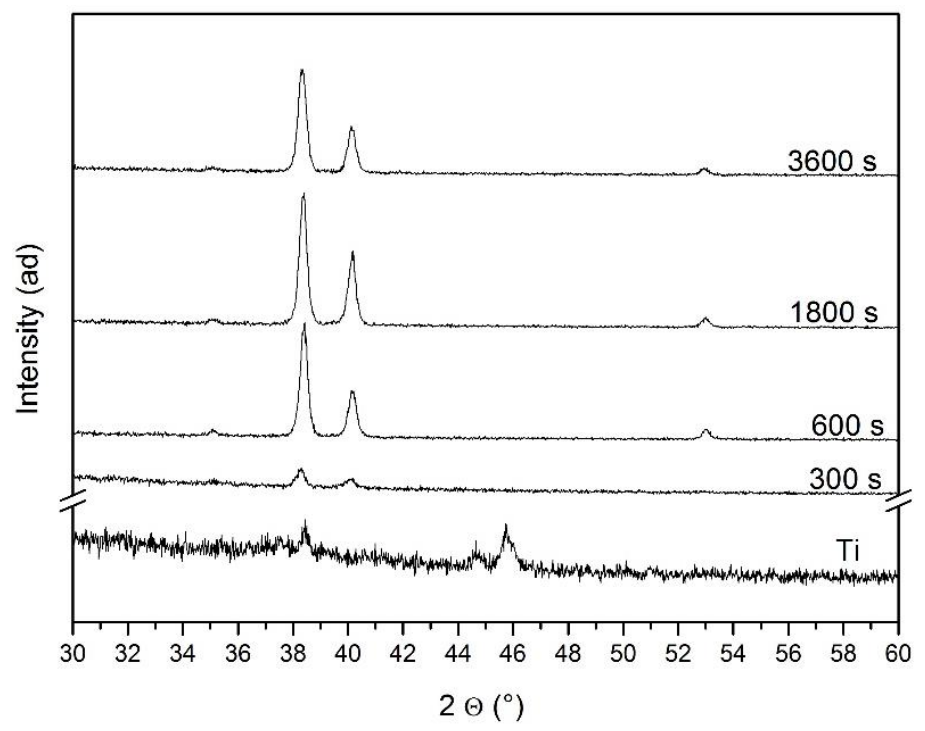

Figure 4: GIXRD diffractograms obtained from the samples anodized in pyroligneous liquor $50 \%$.

Potential transients show, however, that the thickness of the film was evidenced by the increased potential over time that was $8 \mathrm{~V}, 10.5 \mathrm{~V}, 19 \mathrm{~V}$ and $25.5 \mathrm{~V}$ in $300 \mathrm{~s}, 600 \mathrm{~s}, 1800 \mathrm{~s}$ and $3600 \mathrm{~s}$, respectively. The relationship between the potential transients and the diffraction spectrum of the samples indicates that although the film thickness increases, it is still thin. Some authors $[32,40]$ report the appearance of rutile as the only crystalline phase in titanium anodizing at low potentials $(5 \mathrm{~V}$ to $8 \mathrm{~V})$, in low concentration acidic solutions $\left(\mathrm{H}_{2} \mathrm{SO}_{4} \mathrm{X} 0.5 \mathrm{~mol} . \mathrm{L}^{-1}\right)$. However, the appearance of crystalline phases is more associated with porous films [43], formed through sparking, in other words, through dielectric breakdown due to high potential [33] developed during the anodizing, which is not shown by the behavior of potential transients (Figure 2) obtained in this study. According to Arsov et al. [44], oxide crystallization occurs gradually during the anodizing process, and is associated not only to the dielectric breakdown, but also by stresses developed in the formed film [45]. According to Vanhumbeeck et al. [46,47], when the potential reaches 12V, internal stress occur in the oxide giving rise to the rutile phase. In this study, with the increase of film thickness from $600 \mathrm{~s}$ of anodizing, potentials above $10.5 \mathrm{~V}$ and below $25.5 \mathrm{~V}$ are reached, but even so the rutile phase cannot be evidenced by the XDR technique.

Although the literature $[48,49]$ reports a relationship between crystallinity and interfering colors obtained, this effect cannot be completely associated with the result of this study. It can be seen, however, that as the color scale changes from yellow to blue, with increasing anodization time and consequent thickening of the film, the concretions arise, evidencing the beginning of the aging process of the film, agreeing with literature. 
Figure 5 shows SEM micrographs for the samples evaluated in GIXRD (Figure 4). At $600 \mathrm{~s}$ and $1800 \mathrm{~s}$ of anodizing (Figure 5 (a) and (b), respectively), the appearance of small nodules in the oxide film is observed. These nodules are small nuclei of crystalline oxide, mainly formed by the OER [19, 27]. At 600s, the potential reached is $10.5 \mathrm{~V}$, which is in agreement with the literature that points that the crystallinity begins to develop near $10 \mathrm{~V}$.

As seen in all $3600 \mathrm{~s}$ micrographs of anodized samples (Figure 5 (c) and (d)), the nuclei evolve into structures called "like flowers" concretions [23, 48, 50], forming clusters in other parts of the sample. The appearance of "like flowers" concretions indicates that the crystallization is a separation of the oxide from the film, and that concretions reformed mainly of crystalline phase [23,48].
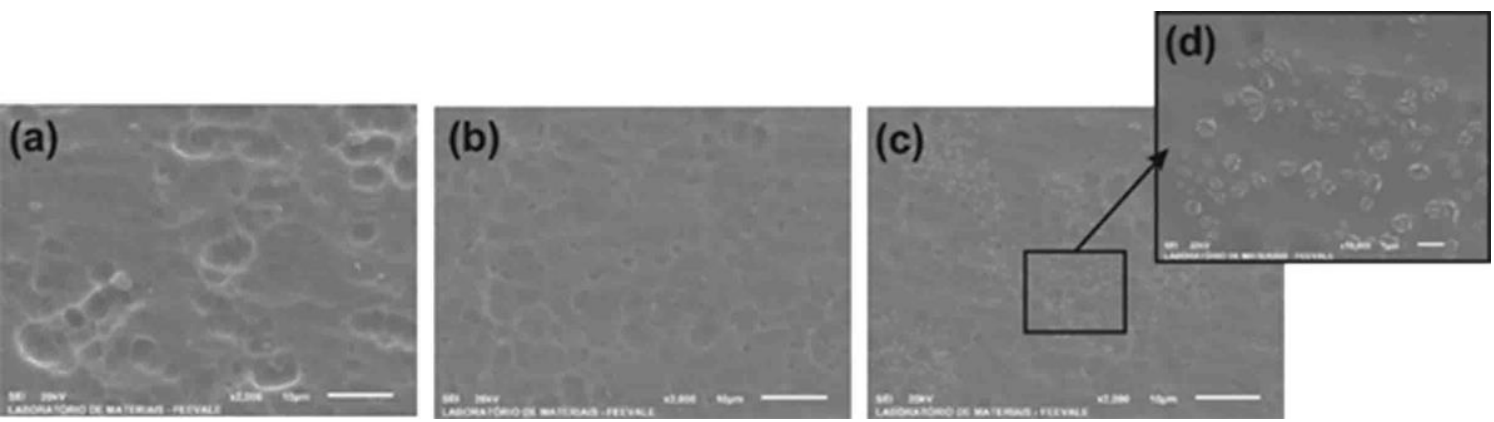

Figure 5: Micrographs of samples anodized in pyroligneous liquor 50\% and analyzed by GIXRD at different times: (a) $600 \mathrm{~s}$; (b) $1800 \mathrm{~s}$; (c) $3600 \mathrm{~s}$; and (d) detail of the surface of the sample anodized at $3600 \mathrm{~s}$, showing clusters of concretions "like flowers".

Micrographs of Figure 5 show that there is a relationship between the anodizing time, with increasing the potential, and the formation of "like flowers". This indicates that there was thickening and aging of the oxide film, which is in according with the literature $[50,51]$. Films appear to be amorphous, and therefore basically formed by suboxides and hydroxides [50], and would not have characteristic crystallization peaks in the GIXRD spectrum, as indeed the anodized sample at 300 s shows. It is suggested that, from $600 \mathrm{~s}$, the suboxides and hydroxides evolve to more complex and crystalline structures of oxides, and finally formed crystal nuclei evolve to form "like flowers" at $3600 \mathrm{~s}$, as evidenced by micrographs of SEM (Figure 5). As the process develops in the galvanostatic mode, with a low current density, the amorphous-crystalline transition appears to occur in a steady state, with slow changes $[48,50]$.

As previously mentioned, the appearance of crystalline phases is closely associated with disruption of the oxide, which behaves as dielectric. However, dielectric breakdown would be associated with sudden drops in transient potential, which does not occur in this study. Liu et al. [27] suggest that the amorphouscrystalline transition of the oxide is associated with the evolution of oxygen. The initial amorphous oxide displays, without difficulties, electronic conductivity. Formation of oxygen bubbles at the oxide/electrolyte interface creates small pores [47], which decrease the area of electronic conductivity and induces the film to create alternatives in order to maintain the electronic transport and hence the features of the electric field formed in the system. These changes are just the arrangement of oxide atoms in an organized manner, in crystal planes and at localized points [50]. Therefore, the dielectric breakdown occurs in a superficial way, which explains the absence of abrupt drop of the generated potential.

\subsection{Analysis of the superficial topography through SEM}

Figure 6 shows a comparison between the sample, as received, and the sample after pickling with $\mathrm{HF}_{\mathrm{HNO}} \mathrm{HN}_{3}$. In Figure 6 (a), there is a formation of elongated risks compatible with the lamination process. A formation of a texture that follows the orientation of the lamination marks is also observed, which probably indicates the presence of native titanium oxide formed in air. Titanium forms a layer that grows spontaneously, and consists primarily of $\mathrm{TiO}$ and $\mathrm{Ti}_{3} \mathrm{O}_{5}$ [40]. This layer is a few nanometers thick and is not porous, similar to the topography found by Fadl-Allah and Mohsen [50] for Ti-CP, although the surface found by the authors did not present evidence so significant of native oxide.

Pickling removes the native oxide layer (Figure 6 (b)), letting the sample with an irregular surface, forming alveoli that suggests the dissolution of substrate parts by acids. This effect on pickling is due to the presence of HF in solution, as monitored by Vermesse et al. [50], in a study of Ti-6Al-4. In that study, it can 
be seen that by gas evolution seen in the process, both the native titanium oxide layer and the base metal react with $\mathrm{HF}$ (the native oxide generates water and $\mathrm{TiF}^{6+}$ complex ions) promoting evolution of hydrogen and formation of $\mathrm{Ti}^{3+}$ ions.
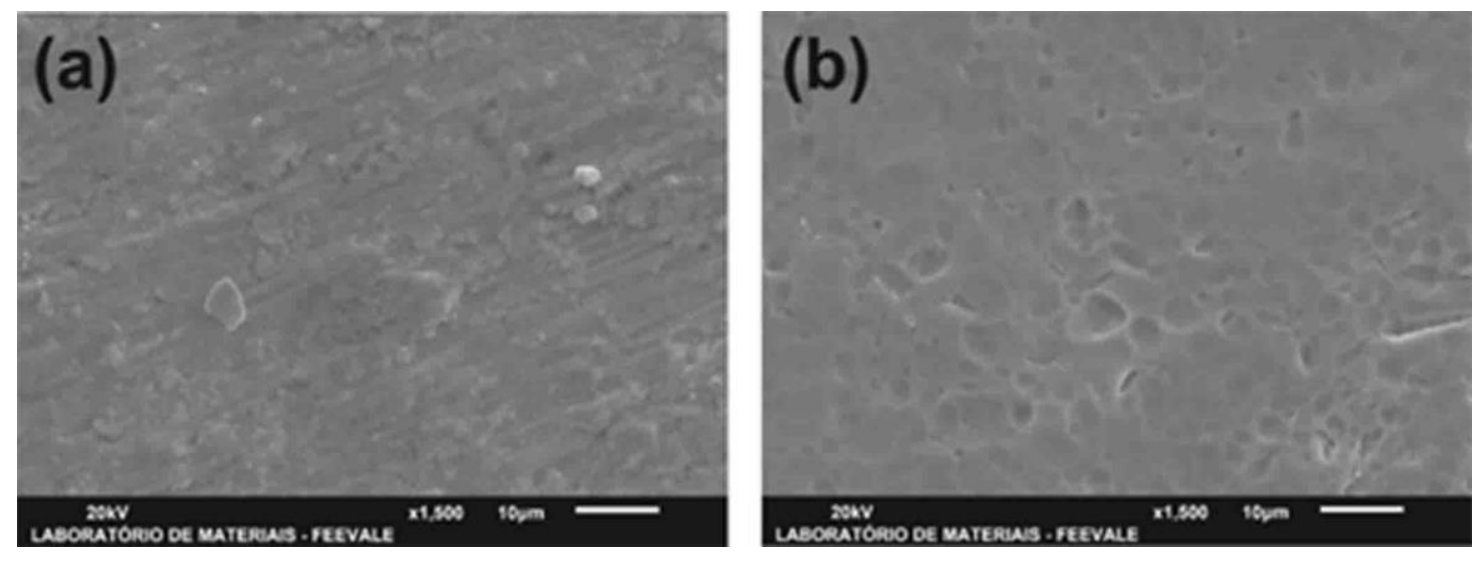

Figure 6: Micrograph of Ti-CP surface of the samples (a) as received and (b) after pickling.

Figure 7 shows the micrographs of samples anodized for shorter process time ( $300 \mathrm{~s}$ and $600 \mathrm{~s}$ ), suggesting that the thickness of the oxide is also small. For titanium potentiostatic anodizing at $10 \mathrm{~V}^{\text {in } \mathrm{H}_{2} \mathrm{SO}_{4}}$ for $3600 \mathrm{~s}$, Xing et al. [19] found similar surface topography to the ones found in this study for short anodizing times. 

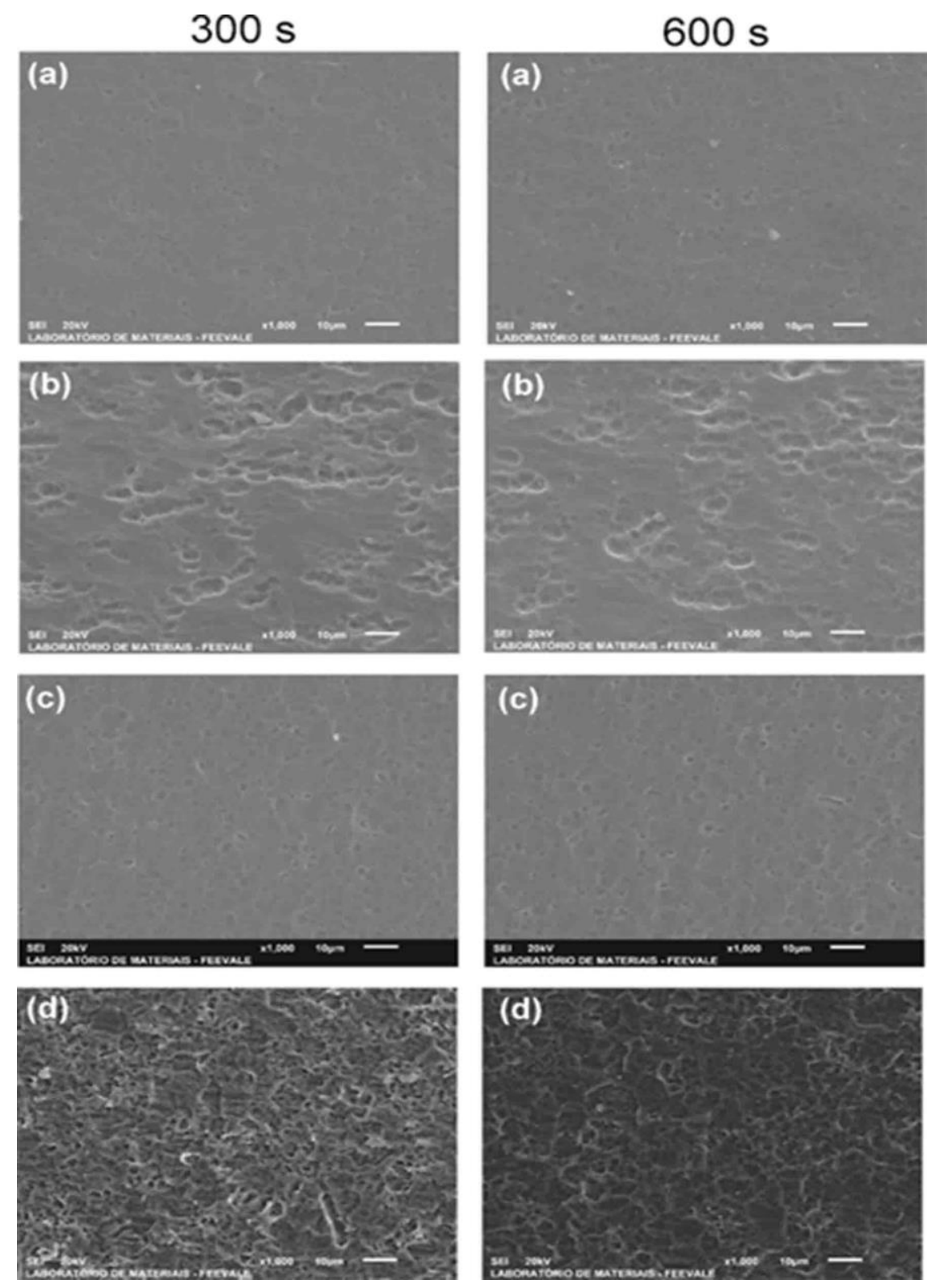

Figure 7: Top view micrographs of samples anodized at $300 \mathrm{~s}$ and $600 \mathrm{~s}$ in the electrolytes: (a) pyroligneous liquor 25\%; (b) pyroligneous liquor 50\%; (c) pyroligneous liquor 100\%; (d) distilled pyroligneous liquor $50 \%$.

It is observed in Figure 7 that the samples after the anodization presented a surface similar to the sample Ti-CP after pickling, Figure 6-b. This result indicates that the oxide film formed after the anodization has a low thickness, maintaining a topography similar to the original Ti sample. There is no pore formation or structures that denote formation of crystalline phases in $300 \mathrm{~s}$ of process, which agrees with the GIXRD spectrum found (Figure 5).

Over time, the anodizing process evolves and the oxide film grows, as evidenced by the increase of potential in $600 \mathrm{~s}$. However, the oxide still seems to be thin, since there is no significant change in the topography of Figure 7 for the anodized samples at $600 \mathrm{~s}$ in relation to the previous ones. The surface of the samples also shows alveolar irregularities arising from the pickling. However, to the samples anodized with raw pyroligneous liquor (50\% and 100\%) and distilled pyroligneous liquor (50\%), formation of protrusions in the form of precipitates isolated at some points of the surface can be seen. In the sample anodized in pyroligneous liquor (25\%) small points also appear, that can be small nuclei of amorphous oxide that grew randomly. These apparently nodular concretions show that the film starts its amorphous-crystalline transition [48,51]. Xing et al. [19] point that for potentials around $10 \mathrm{~V}$, the crystallization process is extremely slow, fact that explains the few and small concretions found in samples at $600 \mathrm{~s}$. 
As for the potential in the beginning of the process, most of the current is used for film growth, as evidenced by linear behavior of potential transient up to $300 \mathrm{~s}$ of anodizing (Figure 1). From $300 \mathrm{~s}$ to $600 \mathrm{~s}$, there is a sharp decrease in growth rate, and the potential rises little, being very close to $10 \mathrm{~V}$.

Figure 8 shows the micrographs of the samples at longer process times (1800 s and $3600 \mathrm{~s})$ for the electrolytes studied. The topography of the surfaces presented the alveoli from pickling, but less pronounced. This indicates that the film is still thin, but without the presence of pores. In pyroligneous liquor $25 \%$, there is no evolution in topography between $1800 \mathrm{~s}$ and $3600 \mathrm{~s}$, but there is thickening of the film, as evidenced by the potential transients (Figure 2). This shows that the film remains amorphous and, in this electrolyte, it follows a slower growth rate compared to other electrolytes.

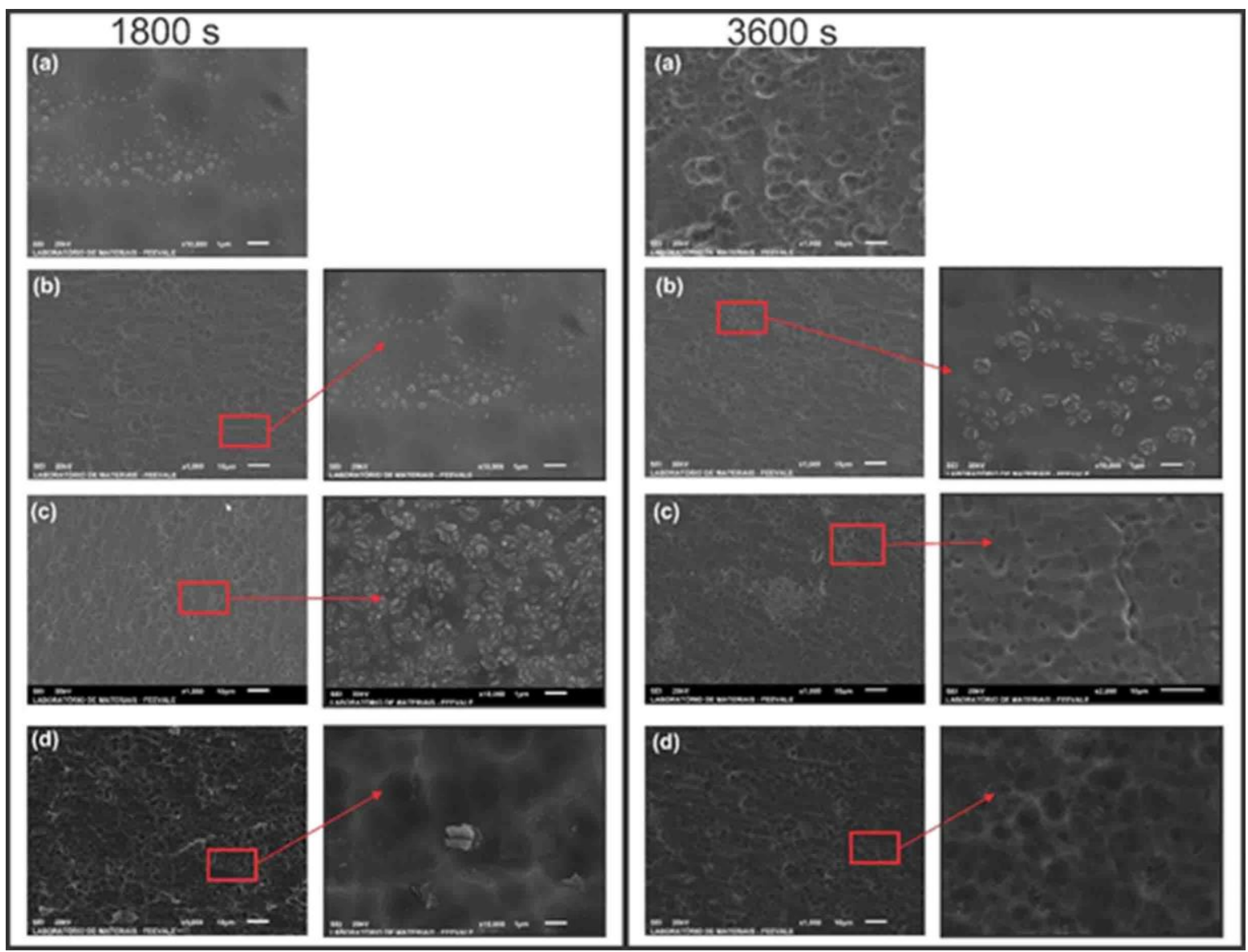

Figure 8: Top view micrographs of samples anodized at $1800 \mathrm{~s}$ and $3600 \mathrm{~s}$ in the electrolytes: (a) pyroligneous liquor $25 \%$; (b) pyroligneous liquor 50\%; (c) pyroligneous liquor 100\%; (d) distilled pyroligneous liquor 50\%.

The concretions, which emerge on the surfaces of the samples in Figure 8, are called "like flowers" due to their shape, and literature suggests that they are crystalline structures of titanium oxide, which evidence a film breaking event $[23,27,33,48,51]$. These structures were found by other authors in various electrolytes such as $\mathrm{H}_{2} \mathrm{SO}_{4}[23,41,48], \mathrm{H}_{3} \mathrm{PO}_{4}$ [30] and sodium acetate [33]. Structures "like flowers", as suggested by the mentioned works, are more strongly correlated with the potential developed than with the nature of the electrolyte used. Bartlett [23] found insipient concretions in $25 \mathrm{~V}$, and Xing et al. [19] and Fadl-Allah and Mohsen [50] at around $30 \mathrm{~V}$. In this study, the concretions on the surfaces begin their formation around $20 \mathrm{~V}$ (Figure 2), and grow preferentially in the alveolar sites originated from the pickling.

In the anodization of $1800 \mathrm{~s}$ in $100 \%$ pyroligneous liquor, an increase in the quantity of concretions in relation to the anodized samples in 50\% pyroligneous liquor and 50\% distilled liquor is observed (Figure 8). This suggests that the speed of the crystallization process is related to the concentration of the electrolyte. This agrees with the results of Diamanti and Pedeferi [21], which suggest that the higher the concentration of the electrolyte, the higher the rate of crystallization of the film.

In fact, in the electrolytes of pyroligneous liquor $50 \%$ and distilled liquor $50 \%$, there is a growth in concretions as well, with increasing anodizing time, (Figure 8). The Figure 8 shows that the concretions in- 
crease in volume over time of anodizing, but seem to decrease in quantity. This is probably due to the aging of the oxide with thickening of the anodized film, or by competition between dissolution processes and formation of oxide. This result agrees with that found by Xing et al. [19] in the potentiostatic anodizing at $30 \mathrm{~V}$ in different times. For potential transients (Figure 2) of the present study, the potentials generated for these samples at $3600 \mathrm{~s}$ were $25.5 \mathrm{~V}$ (pyroligneous liquor 50\%) and $28.5 \mathrm{~V}$ (distilled liquor 50\%).

The sample of pyroligneous liquor $100 \%$ at 3600 s (Figure 8) shows the disappearance of concretions. There is a thickening of the film, evidenced by smoothing the alveolar marks of pickling. A slight crack on the film surface is likely to form in a region of about 30 micrometers.

As there is no evidence of decrease in the potential (Figure 2), this suggests that the crack is superficial and appears because of the thickening of the oxide and the mechanical stresses resulting from this process [28]. Another fact to be mentioned is the disappearance of the concretions in the anodized sample in $3600 \mathrm{~s}$ for pyroligneous liquor $100 \%$. The concretions give place to a slightly rough film, maintaining the original topography, with pickling pores. In accordance to Xing et al. [48], this behavior is characteristic of the aging process of the film. The disappearance of the concretions is associated with the dissolution of the oxide, that is a concurrent process with the oxide formation [27, 48]. As the potential transients of the anodized sample in distilled pyroligneous liquor $50 \%$ were similar to the sample of pyroligneous liquor $25 \%$, it is suggested that the topography of these samples should also be similar, which in fact occurs.

Figure 9 shows the micrographs of sample anodized in AA 1 mol.L-1 for $3600 \mathrm{~s}$ for comparison with other samples analyzed. On the sample surface, it is observed a great quantity of concretions clusters, occupying mainly the alveolar sites originated from pickling. The behavior of this sample is similar to the pyroligneous liquor. Such result suggests that the anodizing agent may be acetic acid present in the pyroligneous liquor. However, the crystallization in pyroligneous liquor seems to have a lower velocity than in pure acetic acid. This can be explained by crystallization that occurs with aging, which in turn is associated with the oxygen evolution reaction (OER). The organic compounds present in the pyroligneous liquor, such as phenols, hemicellulose and aldehydes [20], may be acting as inhibitors of this process, since organic compounds are normally related as having this characteristic [52,53]. They act by blocking the surface of the electrodes (mainly the cathode) by adsorbing their molecules on the metal surface [52,54], which would act to prevent OER.

The literature [52,55] shows that the inhibitory activity increases with the higher concentration of the inhibitory organic compounds, which would explain the low concretion condition in the samples with pure pyroligneous liquor in relation to the sample anodized with $1 \mathrm{~mol}$ AA. L-1. Concerning the behavior of pyroligneous liquor electrolytes, the greater presence of concretions in pure pyroligneous liquor electrolyte may be related to the amount of acetic acid present. Obviously, the $25 \%$ dilution has a lower concentration of this compound than the others, and therefore the OER process (already impaired by the presence of the other compounds of the pyroligneous liquor) and consequent aging of the film is slower than in the other samples of pyroligneous.

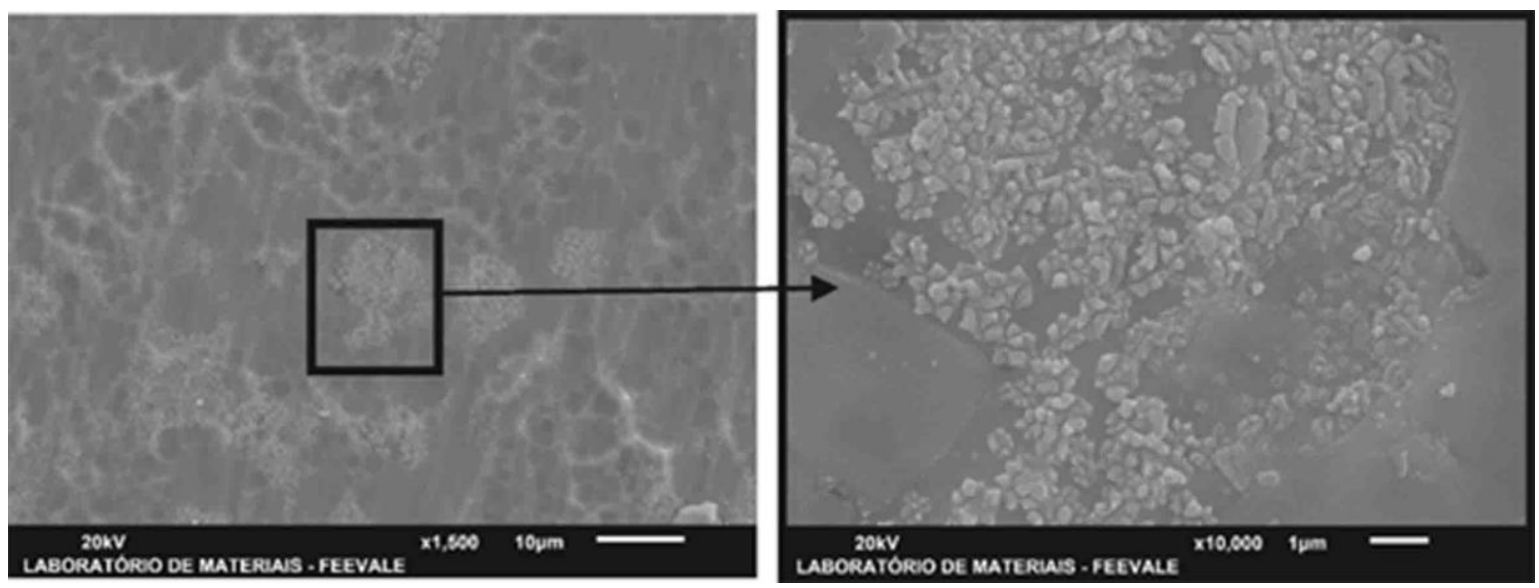

Figure 9: Micrograph of the sample anodized in acetic acid $1 \mathrm{~mol} . \mathrm{L}^{-1}$ at $3600 \mathrm{~s}$.

Although the crystallization behavior is different in the samples, the potential generated (Figure 2) and interfering colors obtained (Figure 3) show that the thicknesses of obtained oxides are similar for all samples, depending on the anodizing time. This agrees with the results of Xing et al. [19] and suggests that the growth of the film and crystallization processes are distinct but interconnected, since it is necessary that 
the film thickens, so that concretions may arise. Crystallization of the film is a gradual process of growth of the initial amorphous oxide.

\section{CONCLUSIONS}

These work presented a study on the anodization of titanium samples with pyroligneous liquor. It was observed that is possible to anodize titanium using different concentrations of pyroligneous liquor. For this it was used the current density of $1 \mathrm{~mA} . \mathrm{cm}^{-2}$ and the maximum potentials obtained were be-tween $25 \mathrm{~V}$ and 30 $\mathrm{V}$.

The GIXRD analyzes showed that the oxide formation process starts amorphously and becomes crystalline. However, SEM analysis showed that the formation of "like flowers" concretions occurs in the anodic films with the increase of anodizing time. Moreover, the oxides obtained by anodizing of titanium with pyroligneous liquor and with acetic acid are very similar, considering the conditions of potential and current density used in this study.

Based on the results presented, it can be concluded that the best results to anodize the titanium were obtained with $50 \%$ pyroligneous liquor diluted in water, obtaining colored surfaces and promoting the formation of crystalline oxides with concretions, mainly in longer process times (3600 s).

\section{ACKNOWLEDGMENTS}

The authors would like to acknowledge the financial support of Fapergs, CNPq and CAPES.

\section{BIBLIOGRAPHY}

[1] CHIDUMAYO, E. N., GUMBO, D. J. "The environmental impacts of charcoal production in tropical ecosystems of the world: A synthesis", Energy for Sustainable Development, v. 17, pp. 86-84, 2013.

[2] ENCARNAÇÃO, F. "Redução do impacto ambiental na produção de carvão vegetal e obtenção do ácido pirolenhoso como alternativa para proteção de plantas", Agroecologia e Desenvolvimento Rural Sustentável, v. 2, n.4, pp. 20-23, 2001.

[3] FROEHLICH P. L., MOURA A. B. D. "Carvão vegetal: propriedades físico-químicas e principais aplicações", Revista Tecnologia e Tendências, v. 9, 2014.

[4] BRUM N. H., BEZZI M. L. "Cultural Region: the construction of cultural identities in Rio Grande do Sul and its manifestation in the regional landscape", Sociedade \& Natureza, v. 20, n.2, pp. 135-155, 2008.

[5] BAILIS R., RUJANAVECH C., DWIVEDI P., et al., "Innovation in charcoal production: A comparative life-cycle assessment of two kiln technologies in Brazil", Energy for Sustainable Development, v. 17, pp. 189-200, 2013.

[6] MUYLAERT M. S., SALA J., FREITAS M. A. V. "The charcoal's production in Brazil - process efficiency and environmental effects", Renewable Energy, v. 16, pp. 1037-1040, 1999.

[7] BARBOSA J. M. S., RE-POPPI N., SANTIAGO-SILVA M. "Polycyclic aromatic hydrocarbons from wood pyrolyis in charcoal production furnaces", Environmental Research, v. 101, pp. 304-311, 2006.

[8] GOMES G. M. F., ENCARNAÇÃO F. "The environmental impact on air quality and exposure to carbon monoxide from charcoal production in southern Brazil", Environmental Research, v. 116, pp. 136-139, 2012.

[9] ANTAL M., GRONLI M. "The art, science, and technology of charcoal production", Industrial \& Engineering Chemistry Research, v. 42, pp. 1619-1640, 2003.

[10] OGAWA M., OKIMORI Y. "Pioneering works in biochar research, Japan", Australian Journal of Soil Research, v. 48, pp. 489-500, 2010.

[11] CAMPOS, A. D. "Técnicas para Produção de Extrato Pirolenhoso para Uso Agricola", Circular Técnica, v. $65,2007$.

[12] KUROMOTO, N. K., SIMÃO, R. A., SOARES, G. A. "Titanium oxide films produced on commercially pure titanium by anodic oxidation with different voltages", Materials Characterization, v. 58, pp. 114-121, 2007.

[13] XIE, Li., LIAO, X., XU, H., et al., "A facile one-step anodization treatment to prepare multi-level porous titania layer on titanium", Materials Letters, v. 72, pp. 141-144, 2012. 
[14] XIE, Li., YIN, G., YAN, D., et al., "Structure, morphology and fibroblasts adhesion of surface-porous titanium via anodic oxidation”, J Mater Sci: Mater Med., v. 21, pp. 259-266, 2009.

[15] QUINTERO, D., et al., "Effect of electrochemical parameters on the formation of anodic films on commercially pure titanium by plasma electrolytic oxidation", Surface and Coatings Technology, v. 258, pp. 1223-1231, 2014.

[16] SUN, C., HUI, R., QU, W., et al., "Effects of processing parameters on microstructures of $\mathrm{TiO}_{2}$ coatings formed on titanium by plasma electrolytic oxidation", Journal of Materials Science, v. 45, pp. 6235-6241, 2010.

[17] RAKOCH, A. G., BARDIN, I. V. “Microarc oxidation of light alloys”, Metallurgist, v. 54, pp. 378-383, 2010.

[18] MATYKINA, E., BERKANI, A., SKELDON P., et al., "Real-time imaging of coating growth during plasma electrolytic oxidation of titanium”. Electrochimica Acta, v. 53, pp. 1987-1994, 2007.

[19XING, J., XIA, Z., HU, J., et al., "Time dependence of growth and crystallization of anodic titanium oxide films in potentiostatic mode", Corrosion Science, v. 75, pp. 212-219, 2013.

[20] FURTADO C. M., STOLZ A. S., PINTO F. L., et al., "Pyroligneous liquor produced from Acacia mearnsii de wild wood under controlled conditions as a renewable source of chemicals", Química Nova, v. 38, pp. 1068-1074, 2015.

[21] DIAMANTI M V., PEDEFERRI M., "Effect of anodic oxidation parameters on the titanium oxides formation", Corrosion Science, v. 49, pp. 939-948, 2007.

[22] DIAMANTI M. V., CURTO B., PEDEFERRI M. "Anodic oxidation of titanium: from technical aspects to biomedical applications”, Journal of Applied Biomaterials \& Biomechanics, v. 9, pp. 55-69, 2011.

[23] BARTLETT L. "An unusual phenomenon observed when anodising CP titanium to produce coloured surfaces for jewellery and other decorative uses”, Optics \& Laser Technology, v. 38, pp. 440-444, 2006.

[24] SUL Y-T., JOHANSSON C. B., JEONG Y., et al., "The electrochemical oxide growth behavior on titanium in acid and alkaline electrolytes”, Medical Engineering \& Physics, v. 23, pp. 329-346, 2001.

[25] SUL Y-T., JOHANSSON C. B., PETRONIS S., et al., "Characteristics of the surfaces oxides on turned and electrochemically oxidized pure titanium implants up to dielectric breakdown: the oxide thickness, micropore configurations, surface roughness, crystal structure and chemical composition", Biomaterials, v. 23, pp. 491-501, 2001.

[26] METROHM. http://www.ecochemie.nl/Products/Echem/NSeriesFolder/PGSTAT302N.

[27] LIU, Z., LIU, H., ZHONG, X., et al., "Characterization of anodic oxide growth on commercially pure titanium in NaTESi electrolyte”, Surface \& Coatings Technology, vol. 258, pp. 1025-10312014.

[28] YOUNG L. “Anodic Oxid Films”, London, Academic Press, 1961.

[29] NAKAJIMA M., MIURA Y., FUSHIMI K., et al., "Spark anodizing behaviour of titanium and its alloys in alkaline aluminate electrolyte”, Corrosion Science, v. 51, pp. 1534-1539, 2009.

[30] KUROMOTO N. K., SIMÃO R. A., SOARES G. A. "Titanium oxide films produced on commercially pure titanium by anodic oxidation with different voltages”, Materials Characterization, v. 58, pp. 114-121, 2007.

[31] DIAMANTI, M. V., CURTO B., PEDEFERRI M. "Interference Colors of Thin Oxide Layers on Titanium”, Color Research \& Application, v. 33, pp. 221-228, 2008.

[32] REGONINI D, BOWEN C. R. "A review of growth mechanism, structure and crystallinity of anodized $\mathrm{TiO}_{2}$ nanotubes”. Materials Science \& Engineering R - Reports, v. 74, pp. 377-406, 2013.

[33] XIE L., LIAO X., XU H., et al., “A facile one-step anodization treatment to prepare multi-level porous titania layer on titanium”, Materials Letters, v. 72, pp. 141-144, 2012.

[34] DELPLANCKE, J-L., DEGREZ, M., FONTANA, A., et al., "Self-colour anodizing of titanium", Surface Technology, v. 16, pp. 153-162, 1982.

[35] DIAMANTI M. V., POZZI P., RANDONE, F., et al., "Robust anodic colouring of titanium: Effect of electrolyte and colour durability”, Materials \& Design, v. 90, pp. 1085-1091, 2016.

[36] VAN GILS, S., MAST, P., STIJNS, E., et al., "Colour properties of barrier anodic oxide films on aluminium and titanium studied with total reflectance and spectroscopic ellipsometry", Surface \& Coatings Technology, v. 185, pp. 303-310, 2004. 
[37] KARAMBAKHSH, A., AFSHAR, A., GHAHRAMANI, S., et al., "Pure Commercial Titanium Color Anodizing and Corrosion Resistance", Journal of Materials Engineering and Performance, v. 20, pp.16901696, 2011.

[38] ZANIOLO K M. “Crescimento anódico e caracterização de óxidos coloridos de titânio em eletrólitos alternativos”, Tese de D.Sc., São Carlos, Universidade Federal de São Carlos, 2014.

[39] SANCHEZ A. G., SCHREINER W., DUFFÓ G., et al., "Surface modification of titanium by anodic oxidation in phosphoric acid at low potentials. Part 1. Structure, electronic properties and thickness of the anodic films”, Surface \& Interface Analysis, v. 45, pp. 1037-1046, 2013.

[40] OSHIDA, Y. "Bioscience and Bioengineering of Titanium Materials", 2 ed., Oxford, Elsevier, 2013.

[41] SONG, H-J., KIM, M-K., JUNG, G-C., et al., "The effects of spark anodizing treatment of pure titanium metals and titanium alloys on corrosion characteristics", Surface \& Coatings Technology, v. 201, pp. 87388745, 2007.

[42] MIZUKOSHI, Y., OHTSU, N., MASAHASHI, N., "Structural and characteristic variation of anodic oxide on pure Ti with anodization duration”, Applied Surface Science, v. 283, pp. 1018-1023, 2013.

[43] MO S-D., CHING W. Y. "Electronic and optical properties of three phases of titanium dioxide: Rutile, anatase, and brookite", Physical Review B., v. 51, pp. 13023-13032, 1995.

[44] ARSOV L. D., KORMANN C., PLIETH W. "In Situ Raman Spectra of Anodically Formed Titanium Dioxide Layers in Solutions of $\mathrm{H}_{2} \mathrm{SO}_{4}, \mathrm{KOH}$, and $\mathrm{HNO}_{3}$ ", Journal of The Electrochemical Society, v. 138, pp. 2964-2970, 1991.

[45] LEACH J. S. L., PEARSON B. R. "Crystallization in anodic oxide films”, Corrosion Science, v. 28, pp. 43-56, 1988.

[46] VANHUMBEECK, J.F., PROOST, J., "On the Relation Between Growth Instabilities and Internal Stress Evolution during Galvanostatic Ti Thin Film Anodization”, Journal of The Electrochemical Society, v. 155, pp. 506-514, 2008.

[47] VANHUMBEECK, J-F., TIAN, H., SCHRYVERS, D., et al., "Stress-assisted crystallisation in anodic titania”, Corrosion Science, v. 53, pp. 1269-1277, 2011.

[48] XING, J., XIA, Z., HU, J., et al., "Time dependence of growth and crystallization of anodic titanium oxide films in potentiostatic mode", Corrosion Science, v. 75, pp. 212-219, 2013.

[49] ZHANG, L., DUAN, Y., GAO, R., et al., "The Effect of Potential on Surface Characteristic and Corrosion Resistance of Anodic Oxide Film Formed on Commercial Pure Titanium at the Potentiodynamic-Aging Mode”, Materials, v. 12, pp. 370-388, 2019.

[50] VERMESSE E., MABRU C., ARURAULT L. "Surface integrity after pickling and anodization of Ti6Al-4V titanium alloy”, Applied Surface Science, v. 285, pp. 629-637, 2013.

[51] FADL-ALLAH, S. A., MOHSEN ,Q. "Characterization of native and anodic oxide films formed on commercial pure titanium using electrochemical properties and morphology techniques", Applied Surface Science, vol. 256, pp. 5849-5855, 2010.

[52] LUKOVITS, I., KÁLMÁN, E., ZUCCHI, F. "Corrosion Inhibitors-Correlation between Electronic Structure and Efficiency”, Corrosion, v. 57, pp. 3-8, 2001.

[53] SOLMAZ, R., ALTUNBAŞ, E., KARDAŞ, G. "Adsorption and corrosion inhibition effect of 2-((5mercapto-1,3,4-thiadiazol-2-ylimino)methyl)phenol Schiff base on mild steel". Materials Chemistry And Physics, vol. 125, pp. 796-801, 2011.

[54] ROCHA, J. C., GOMES, J. A. C. P., D’ELIA, E. "Corrosion inhibition of carbon steel in hydrochloric acid solution by fruit peel aqueous extracts”. Corrosion Science, v. 52, pp. 2341-2348, 2010.

[55] ABDALLAH, M., ASGHAR, B.H., ZAAFARANY, I., et al., "The Inhibition of Carbon Steel Corrosion in Hydrochloric Acid Solution using Some Phenolic Compounds", International Journal Of Electrochemical Science, v. 7, pp. 282-304, 2012. 


\section{ORCID}

Luciane Taís Fuhr

https://orcid.org/0000-0001-8053-3613

Ângela Beatrice Dewes Moura

https://orcid.org/0000-0001-7200-1668

Carlos Leonardo Pandolfo Carone

https://orcid.org/0000-0002-4084-4502

Fernando Dal Pont Morisso

https://orcid.org/0000-0002-9653-9857

Leonardo Felix Scheffel

Sandra Raquel Kunst

Jane Zoppas Ferreira

https://orcid.org/0000-0002-3502-7225

https://orcid.org/0000-0002-8060-3981

https://orcid.org/0000-0002-3137-297X

Cláudia Trindade Oliveira

https://orcid.org/0000-0002-4472-5359 